\title{
INFLUENCE OF ENVIRONMENTAL FACTORS IN THE ATMOSPHERIC CORROSION OF COPPER IN THE PRESENCE OF PROPIONIC ACID
}

\author{
A. ECHAVARRÍA, F. ECHEVERRÍA*, H. GIL AND C. ARROYAVE \\ Corrosion and Protection Group, University of Antioquia, Medellin, Colombia \\ (Received:July 21, 2008 - Accepted: May 28, 2009)
}

\begin{abstract}
Exposure time, pollutant concentration, and relative humidity (RH) are important environmental variables for the atmospheric corrosion of copper in the presence of propionic acid vapors. This paper shows the most outstanding results into the effect of these variables. This study was carried out by mean of exposures at dynamic conditions in 260,380 , and 680 ppbv propionic acid, with relative humidities of $70 \%$ and $90 \%$. The effect of the propionic acid was also evaluated in static conditions with 4, 40, and 120 ppmv propionic acid with relative humidities of $40 \%, 80 \%$, and $100 \%$ RH. All the samples were evaluated by triplicate within 21 days of exposure. The corrosion rate was used to quantify the degradation of copper by mean of weight loss and coulometric reduction technique. Coulometric reduction indicates that the charge needed to reduce the oxides increases as exposure time, relative humidity and pollutant concentration increases. On the other hand, the corrosion rate determined gravimetrically, confirms that at a higher relative humidity and higher propionic acid concentration the copper deterioration is also higher.
\end{abstract}

\section{INTRODUCTION}

Volatile organic compounds in the atmosphere (VOC) have different hydrocarbons and organic acid vapors. The most important organic acids in the atmosphere are formic, acetic, propionic, butyric and oxalic acid. The emissions of these types of acids can be either biogenic or anthropogenic, and they contribute to the total acidity of the rain in the urban areas. The corrosion originated by these vapors on different metals and their alloys (lead, steel, nickel, copper, cadmium, magnesium, zinc) is a phenomenon that has been observed for some time ${ }^{1}$. Graedel ${ }^{2}$ finds that the anions of organic acids (acetates and in smaller amount, formates) constitute between 0.1 and $1 \%$ of the total ion concentration in the copper patina exposed in outdoor atmospheres by long periods of time. Copper is corroded in presence of organic acids such as formic, acetic and butyric ${ }^{3-10}$. It has been found that the corrossivity of the organic acids vapors in ppmv (parts per million in volume) level on copper is given in the following order (from the highest to the lowest aggressiveness level) acetic $>$ formic $>$ butyric $^{7,9-10}$.

On the other hand, the initial growth of corrosion products on copper has been successfully characterized during exposure to formic acid, acetic acid and propionic acid in ppbv (parts per billion in volume), both quantitatively and chemically, by the combination of IRAS/QCM, electrolytic reduction of corrosion products and $\mathrm{AFM}^{11-13}$. The results shows the formation of two kind of copper (I) oxides, named crystalline and amorphous identified by coulometric reduction.

Coulometric and potentiodynamic reduction, and corrosion rate measurements by the weight loss method are broadly used techniques for the study of the corrosivity of copper in different environments ${ }^{14-16}$. The purpose of this laboratory study is to contribute to the understanding of the copper corrosion in presence of propionic acid by mean of reduction charge quantification for the different corrosion compounds formed in this atmosphere. Additionally, coulometric reduction measurements were used to compare them with the gravimetric estimation.

\section{EXPERIMENTAL}

Two corrosive atmospheres were evaluated for low and high pollutant concentration ${ }^{17}$. The first one was carried out in a climatic chamber with a pollutant dosage level of ppbv, under dynamic conditions. Those of high concentration were carried out in a closed chamber (glass vessel) under static conditions.

Exposures performed in climatic chamber- A climatic chamber was used, in which an "oil less" dentistry compressor produced clean air for the experiments. It gives clean air directed to a pretreatment system made of an activated carbon filter, a zero purifier air "PEAK", and two particulate matter filters $(0.25$ and $0.05 \mu \mathrm{m})$. Permeation tubes, used for the liquid propionic acid were calibrated for different emission rates. The permeation was gravimetrically certificated. Usually, values of $90 \pm 2 \% \mathrm{RH}$ and $70 \pm 2.5 \%$
RH were obtained with a constant air flow of $4 \mathrm{~L} \mathrm{~min}^{-1}$. To obtain the desired propionic acid concentration as a vapor, an ideal gas behavior is assumed for the air of the system ${ }^{16}$. So, the propionic acid concentration in the vapor phase can be calculated as:

$$
C v=\frac{E R * 29.5}{4 * 74.08} \quad(\mathrm{ppbv})
$$

where, $\mathrm{Cv}$ is the propionic acid concentration expressed in parts per billion in volume (ppbv); ER is the emission rate of the tubes $(2650 \pm 70,3750 \pm$ 80 and $\left.6950 \pm 100 \mathrm{ng} \cdot \mathrm{min}^{-1}\right) ; 29.5$ is the molar volume $\left(\mathrm{L} \cdot \mathrm{mol}^{-1}\right)$ of the air in laboratory conditions, $30^{\circ} \mathrm{C}$ and $640 \mathrm{~mm} \mathrm{Hg} ; 4$ is the nominal flow of air $\left(\mathrm{L} \cdot \mathrm{min}^{-1}\right)$ located in Medellin, Colombia $1450 \mathrm{ASL}$, and 74.08 is the molecular weight $\left(\mathrm{g} \cdot \mathrm{mol}^{-1}\right)$ of the propionic acid $\left(\mathrm{CH}_{3} \mathrm{CH}_{2} \mathrm{COOH}\right)$.

Copper samples of dimensions $1.0 \times 1.5 \times 0.01 \mathrm{~cm}$, Merck $(<0.002 \% \mathrm{Ag}$, $0.05 \% \mathrm{~Pb}, 0.01 \% \mathrm{Sn}, 0.005 \% \mathrm{Fe}, 0.005 \% \mathrm{Mn}, 0.0002 \% \mathrm{As}$ ) were polished with silicon carbide papers up to 600 mesh, degreased with acetone, flushed with cold air, and immediately placed in the exposure chamber. The samples were exposed to propionic acid during 7, 14, and 21 days. The experiments were performed with 260,380 , and 690 ppbv propionic acid.

Exposures performed in closed chamber- Experiments carried out in static conditions were performed at $30 \pm 0.8^{\circ} \mathrm{C}$ inside a glass vessel dessicators, contained a diluted propionic acid solution. Pollutant concentration of 4, 20, 40, and $120 \mathrm{ppmv}$ propionic acid were used for a duration of 21 days. The solution was renewed weekly to avoid the degradation of the organic compound.

For low relative humidity conditions, the dessicator was provided with a saturated solution of $\mathrm{K}_{2} \mathrm{CO}_{3} .2 \mathrm{H}_{2} \mathrm{O}$ and $\mathrm{NH}_{4} \mathrm{Cl}$ to obtain $40 \%$ and $80 \% \mathrm{RH}$ according to ASTM E104-85 standard $^{8,18-19}$. The relative humidity condition near to $100 \%$ was obtained placing a recipient with $500 \mathrm{~mL}$ propionic acid solution in the bottom of the dessicator. To produce the propionic acid vapor in static atmosphere, the procedure already described elsewhere, was followed to determine the deterioration of copper in acetic and formic acid atmospheres ${ }^{3-}$ 10 .

Pollutant concentration of propionic acid vapor in a closed atmosphere was calculated using the relationship between partial pressure and the Raoult's law, adapted from a procedure reported in the literature ${ }^{3-10}$.

$$
C v=\frac{p_{H(\operatorname{Pr} o)}}{P_{T}}=\frac{G * M_{H_{2} O}}{1000 * M_{H(\operatorname{Pr} o)} * P_{T}} \cdot 10^{8.8519-\frac{2454.02}{T}}
$$

where $p_{H(P r o)}$ is the partial pressure of the propionic acid in the dessicator's atmosphere, the term is the vapor partial pressure of the pure propionic acid $(\mathrm{mm} \mathrm{Hg}), \mathrm{T}$ is the temperature in Kelvin, $\mathrm{G}$ is the propionic acid mass in grams in a $1000 \mathrm{~mL}$ solution, $\mathrm{MH}_{2} \mathrm{O}$ and $\mathrm{MH}(\mathrm{Pro})$ are the molecular weights of the water and the propionic acid respectively, and PT is the total pressure under the 
laboratory's conditions (640 mm Hg for Medellín city).

For exposure in atmospheres with 4, 20, 40, and $120 \mathrm{ppmv}(\mathrm{Cv})$, the amounts of propionic acid and the water used for a volume of $500 \mathrm{ml}$ solution are shown in Table I.

Table I.- Amount of propionic acid added to $500 \mathrm{ml}$ of water to obtain pollutant concentration of $4,20,40$, and 120 ppmv.

\begin{tabular}{|c|c|c|c|c|}
\hline $\begin{array}{c}\text { Acid concentration in the air } \\
(\mathrm{ppmv})\end{array}$ & 4 & 20 & 40 & 120 \\
\hline $\begin{array}{c}\text { Amount of propionic acid } \\
(\mathrm{mL})\end{array}$ & 0.9 & 4.6 & 9.3 & 27.9 \\
\hline $\begin{array}{c}\text { Amount of water }(\mathrm{mL}) \\
\text { Amo }\end{array}$ & 499.1 & 495.4 & 490.7 & 472.1 \\
\hline
\end{tabular}

Techniques to measure the corrosion degree-The coulometric reduction technique was carried out according with the ASTM standard B825 - $97^{13}$. ACM Instruments Research Potenciostat equipment was used along with a CAR ZRA (Zero Resists Ammeter) to measure the potential of the sample, by using three electrodes with a saturate calomel electrode (SCE) as the reference and platinum as counter electrode. The electrolytic solution was $0.1 \mathrm{M} \mathrm{KCl}$, purged with Nitrogen for 30 minutes before and during the reductions. The current density was the same in all the measurements, and the value was selected according to the corrosion degree of the sample, so that the reductions were done in less than an hour. Three samples were used to carry out the galvanostatic experiments.

The gravimetric analyses were done using coupons of $0.24 \mathrm{dm}^{2}$, during 21 days of exposure. The corrosion products were removed by using an ultrasonic bath in $10 \% \quad \mathrm{H}_{2} \mathrm{SO}_{4}$ (per volume) solution with immersion times of three minutes each sample at room temperature, according to the ASTM G1 - 90 standard $^{17}$. The measurements were done using an analytical scale with accuracy of $\pm 0.1 \times 10^{-3} \mathrm{~g}$. Three replicas were used during the experiments. The results were statistically treated with the STATGRAPHICS software.

\section{RESULTS AND DISCUSSION}

Coulometric reduction curves obtained with dynamic conditions-Fig. 1 shows the coulometric reduction curves of copper samples exposed to 380 ppbv, $90 \% \mathrm{RH}$, and $30^{\circ} \mathrm{C}$ during 7,14 , and 21 days. The reduction curves were performed at $25 \mu \mathrm{A} . \mathrm{cm}^{-2}$ current density. A plateau around $-0.5 \mathrm{~V}_{\mathrm{SCE}}$ appeared, corresponding to the amorphous cuprite reduction ${ }^{15-22}$. This is consistent with previously published results for the same exposure conditions ${ }^{10}$. A second plateau, close to $-0.75 \mathrm{~V}_{\mathrm{SCE}}$, can be discerned associated to the intermediate cuprite reduction ${ }^{23}$, that has been observed in exposures of copper in a clean humidity environment. Finally, we can see a final plateau around $-1.15 \mathrm{~V}_{\mathrm{SCF}}$ corresponding to the hydrogen reduction, that is the final reduction step s-10,15-22 $^{\text {. }}$. To perform a more complete electrochemical characterization of the copper compounds, it is necessary to calculate the derivative curve of the reduction curves.

Fig. 2 shows the reduction curve and its derivative for a copper sample exposed during 21 days at $680 \mathrm{ppbv}$. The minimum of the derivative curve, it is the transition of the reduction between the different oxides, namely amorphous, intermediate, and crystalline cuprite and for last hidrogen. The crystalline cuprite that appears around $-1 \mathrm{~V}$ is seen from Fig. 2, and it was found from all exposure times. These compound is the "bulk" cuprite that is form for longer exposure times ${ }^{23}$. All the coulometric reduction curves were compared with the electric charge amount, that is, the current density applied times the testing time. Under constant current conditions, the total charge consumed, $\mathrm{Q}(\mathrm{t})$, coul. $\mathrm{cm}^{-2}$, between the beginning of the test and other time could be calculate as:

$$
Q(t)=I^{*} t \quad\left(\text { coul. } \mathrm{cm}^{-2}\right)
$$

where $\mathrm{I}$ is the current density used in the experiment, A. $\mathrm{cm}^{-2}$.

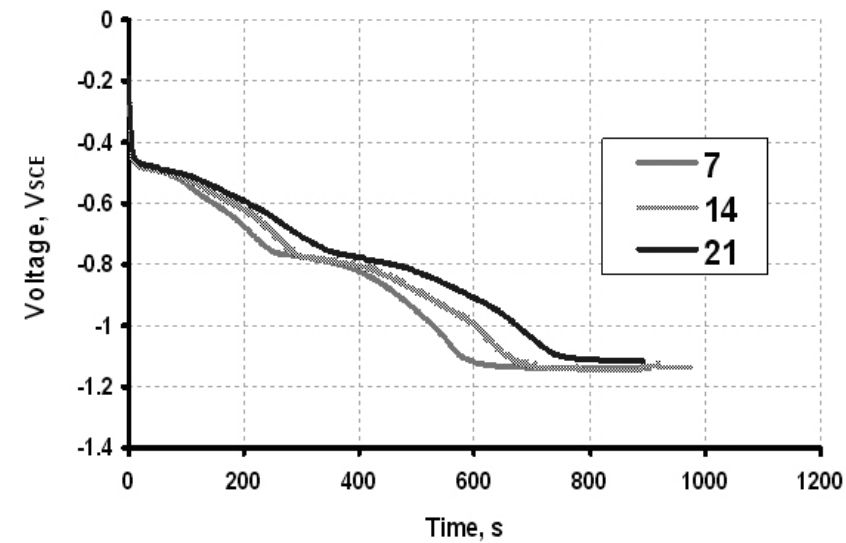

Figure 1.- Coulometric reduction curves of copper in deareated $0.1 \mathrm{M} \mathrm{KCl}$ solution $\left(\mathrm{I}=25 \mu \mathrm{A} \cdot \mathrm{cm}^{-2}\right)$ after exposure to $380 \mathrm{ppbv}, 90 \% \mathrm{RH}$ and $30^{\circ} \mathrm{C}$, for 7,14 , and 21 days.

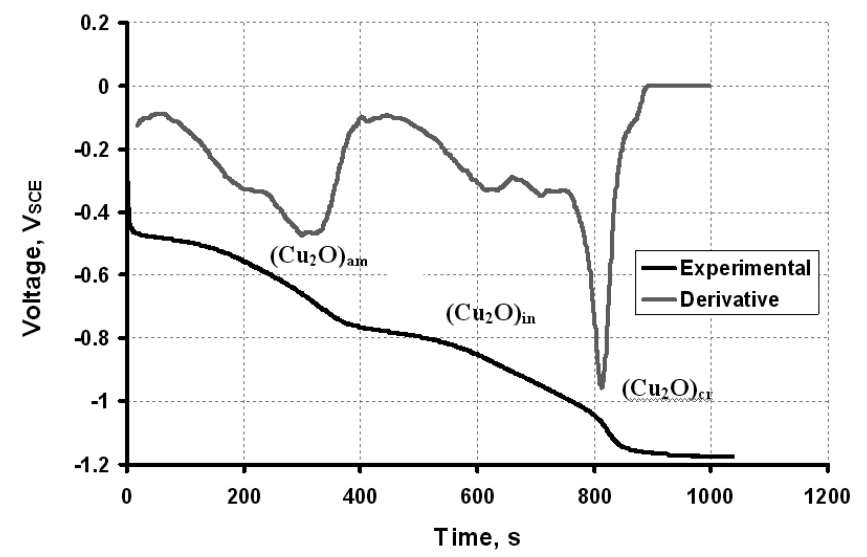

Figure 2.- Coulometric reduction curve and its derivative of copper in deareated $0.1 \mathrm{M} \mathrm{KCl}$ solution $\left(\mathrm{I}=25 \mu \mathrm{A} . \mathrm{cm}^{-2}\right.$ ) after exposure to $680 \mathrm{ppbv}, 90 \%$ $\mathrm{RH}, 30^{\circ} \mathrm{C}$ for 21 days.

Fig. 3 displays the coulometric reduction curves of copper samples exposed in synthetic air at $90 \% \mathrm{RH}$ after exposure to 260,360 , and $680 \mathrm{ppbv}$. It is possible to see that, the reduction time increases with increasing the propionic acid concentration. This effect is reflected in a thicker intermediate and crystalline cuprite layer. It is interesting to stress out that, coulometric reduction curves shows detectable changes according to the exposure level, although visually appreciable differences are not observed on the samples evaluated under dynamic conditions (ppbv).

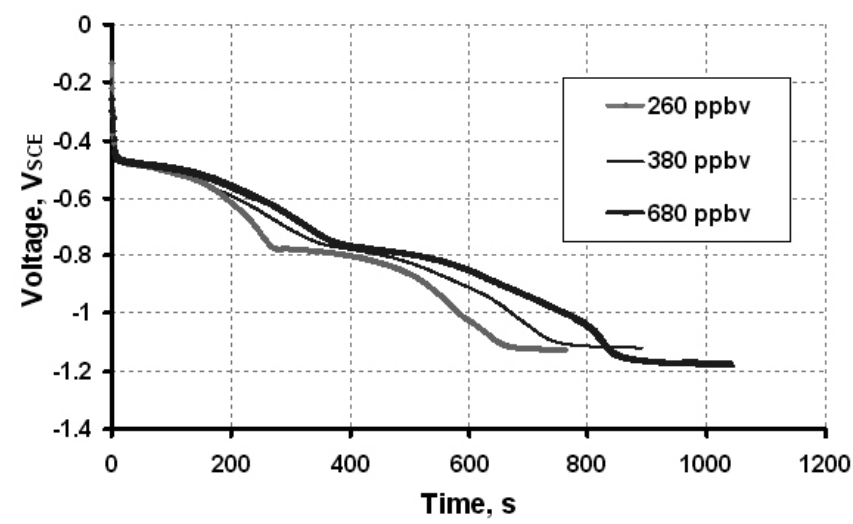

Figure 3.- Coulometric reduction curves of copper in deareated $0.1 \mathrm{M} \mathrm{KCl}$ solution $\left(\mathrm{I}=25 \mu \mathrm{A} . \mathrm{cm}^{-2}\right)$ after exposure to 260,380 , and $680 \mathrm{ppbv}$ of propionic acid for 21 days. 
Coulometric reduction curves obtained from static conditions-Figure 4 exhibit the results for copper exposed during static conditions in propionic acid at $100 \%$ RH. To obtain the total charge consumed in the reduction of the copper oxides, the ISO TC 156/WG 4 - N $378^{24}$ standard criteria was followed. These criteria, allow us to determine the total reduction time from the beginning of the experiment until the hydrogen reduction stage, obtained as the minimum of the derivative curve of the potential versus time data. The average value of hydrogen evolution $\left(\mathrm{V}_{\mathrm{H}}-1.03 \mathrm{~V}_{\mathrm{SCE}}\right)$ was fixed in these curves. This was performed in order to have a reference of the consumed charge value for the total reduction of the oxides, but also, to compare all the results obtained. The term "Qox" is defined as the charge $\left(\right.$ coul. $\left.\mathrm{cm}^{-2}\right)$ to complete the oxide reduction of the sample.

The corrosion rate measured as the total reduction charge increases with increasing the exposure time. Additionaly, we found higher reduction charge values from the static condition than for the dynamic one, at least at high relative humidities.

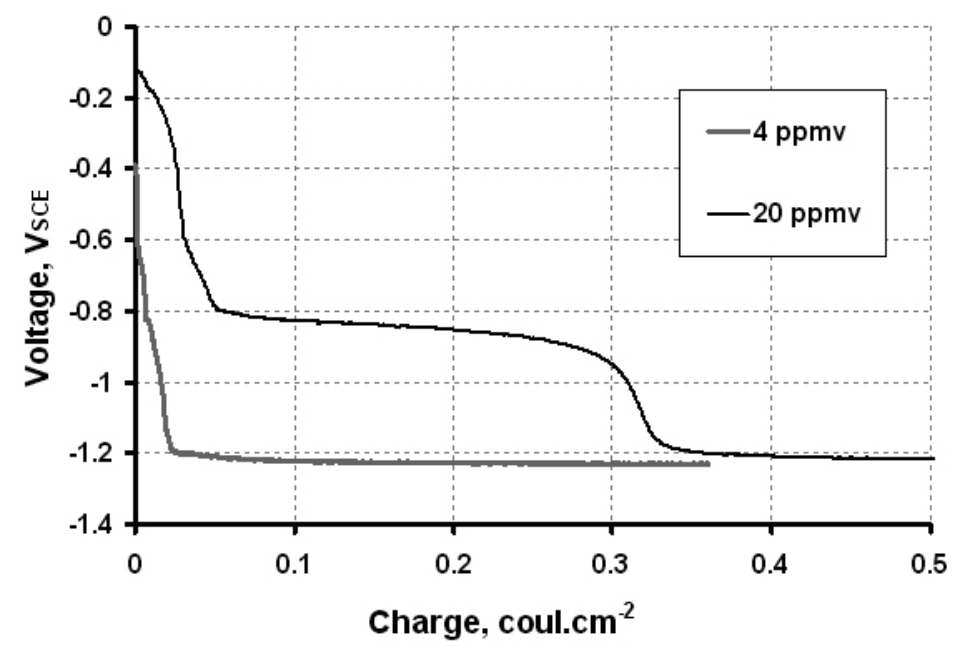

Figure 4.- Coulombimetric curves of copper samples exposed to static condition during 21 days in 4 and 20 ppmv propionic acid at $30{ }^{\circ} \mathrm{C}$.

Table II shows the charge values for the amorphous cuprite reduction $\left(\mathrm{Cu}_{2} \mathrm{O}\right)_{\text {am }}$, intermediate cuprite reduction $\left(\mathrm{Cu}_{2} \mathrm{O}\right)_{\text {in }}$, and the crystalline cuprite reduction $\left(\mathrm{Cu}_{2} \mathrm{O}\right)_{\mathrm{cr}}$ deduced from the coulometric reduction curves. The values are calculated for 21 days of exposure, in both, ppbv (dynamic) and ppmv (static). As it can be deduced from Table II, the total electric charge for the oxide reduction; which corresponds to the presence of three type of copper (I) oxide in the sample, increase slightly as the pollutant concentration increases up to $4 \mathrm{ppmv}$, from 0.0134 to $0.0155 \mathrm{coul}^{\mathrm{cm}} \mathrm{cm}^{-2}$. However, a drastic cuprite increase is detected in exposures with 40 ppmv. In this case, the reduction charge was 0.3094 after 21 days.

Table II.- Reduction charge for three different type of coper (I) oxide obtained by coulometric reduction for 21 days of exposure.

\begin{tabular}{|c|c|c|c|c|c|}
\hline $\begin{array}{l}\text { Propionic acid } \\
\text { concentration }\end{array}$ & RH (\%) & $\underset{\mathrm{Q}_{\mathrm{ox}}}{\left(\mathrm{Cu}_{2} \mathrm{O}\right)_{\mathrm{am}}}(\mathrm{coul}$ & 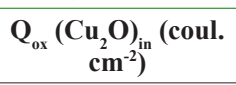 & $\underset{0 \times}{\mathrm{Q}_{0 \mathrm{x}}\left(\mathrm{Cu}_{2} \mathrm{O}\right)_{\mathrm{cr}}}(\mathrm{coul}$. & $Q_{o x}$ total $\left(\right.$ coul.cm $\left.{ }^{-2}\right)$ \\
\hline $260 \mathrm{ppbv}$ & 70 & $0.0029 \pm 0.001$ & $0.0026 \pm 0.003$ & $0.0079 \pm 0.003$ & $0.0134 \pm 0.003$ \\
\hline $260 \mathrm{ppbv}$ & 90 & $0.0047 \pm 0.001$ & $0.0015 \pm 0.003$ & $0.0080 \pm 0.003$ & $0.0142 \pm 0.003$ \\
\hline $380 \mathrm{ppbv}$ & 90 & $0.0036 \pm 0.001$ & $0.0028 \pm 0.002$ & $0.0100 \pm 0.002$ & $0.0164 \pm 0.002$ \\
\hline $680 \mathrm{ppbv}$ & 90 & $0.0079 \pm 0.001$ & $0.0084 \pm 0.003$ & $0.0041 \pm 0.003$ & $0.0204 \pm 0.003$ \\
\hline $4 \mathrm{ppmv}$ & 100 & --------- & $0.0085 \pm 0.010$ & $0.0695 \pm 0.010$ & $0.0155 \pm 0.010$ \\
\hline $40 \mathrm{ppmv}$ & 100 & $0.0201 \pm 0.006$ & $0.0199 \pm 0.03 *$ & $0.2694 \pm 0.03 *$ & $0.3094 \pm 0.03 *$ \\
\hline
\end{tabular}

Effect of the exposure time-The reduction charge $\left(\mathrm{coul}_{\mathrm{cm}} \mathrm{cm}^{-2}\right)$ for the complete reduction of the corrosion products during the coulometric reduction experiments, lineally increases with increasing the exposure time. This value directly depends on the corrosion product amount. Figure 5 compares the charge values for the reduction in function of the exposure time for three propionic acid concentration in the air $(260,380$, and $680 \mathrm{ppbv})$ at $90 \% \mathrm{HR}$ and $30{ }^{\circ} \mathrm{C}$. The error bars refers to the confidence interval of $95 \%$. In all cases, corrosion rate expressed as reduction charge, increases and it can be discerned for each other. Exposures at $680 \mathrm{ppbv}$ propionic acid produces more corrosion, corresponding with a thicker copper (I) oxide as is seen in Table II.

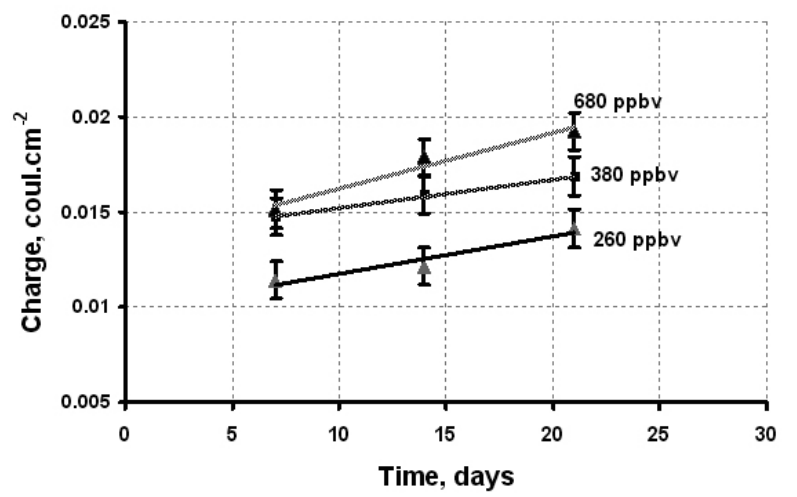

Figure 5.- Relationship between the reduction charge value for in function of the exposure time for three different concentrations of propionic acid (260, 380 , and $680 \mathrm{ppbv}$ ) at $90 \% \mathrm{HR}$ and $30^{\circ} \mathrm{C}$. 
Figure 6 shows the variation between the reduction charge of the copper oxide in function of the exposure time, for exposures with 4 and $20 \mathrm{ppmv}$ at $100 \% \mathrm{HR}$ and $30^{\circ} \mathrm{C}$. In both cases, a lineal behavior is seen, with a greater slope obtained in exposures at $20 \mathrm{ppmv}$. When comparing with the results from dynamic conditions, see Fig. 5, we can conclude that the static environment produce greater corrosion rates. This may be explained because under static atmospheres, the pollutant remains longer time on the copper surface. Additionally, the relative humidity reach constant values when is controlled into a dessicator, generating enough water monolayers to produce appreciable degradation on the copper surface. But, when it is used dynamic conditions, the relative humidity varies with a relative accuracity of $\pm 5 \%$, changing the actual water monolayers and producing less corrosion rates.

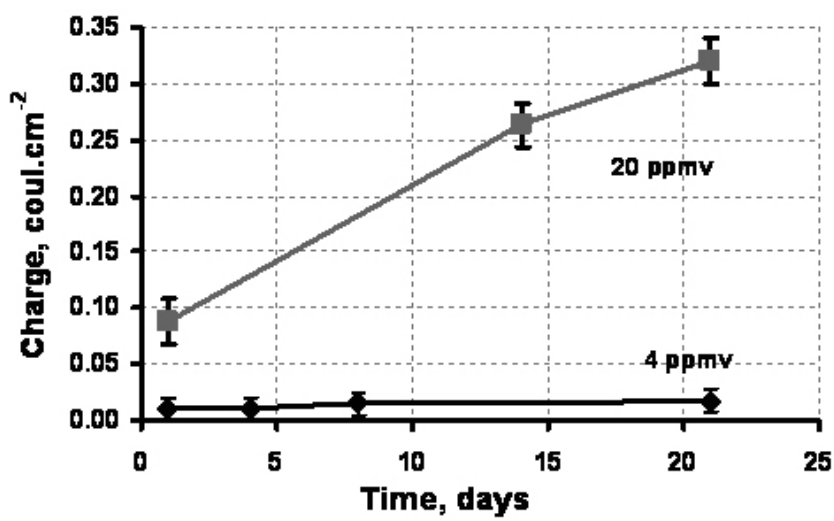

Figure 6.- Relationship between the reduction charge value for copper oxide reduction in function of the exposure time for 4 and $20 \mathrm{ppmv}$ of propionic acid at $100 \% \mathrm{RH}$ and $30^{\circ} \mathrm{C}$.

Effect of the relative humidity and propionic acid concentration-Figure 7 compares the reduction charge against the exposure time for exposures in 260 ppbv with relative humidities of 70 and $90 \%$. It is found that at higher relative humidity the charge value is increased during the reduction; therefore, exist an increment of the copper corrosion degree. On the other hand, Fig. 8 shows the gravimetric corrosion rate obtained during dynamic exposures in ppmv level for relative humidities of 40,80 and $100 \%$ and 4,40 , and 120 ppmv during 21 days.

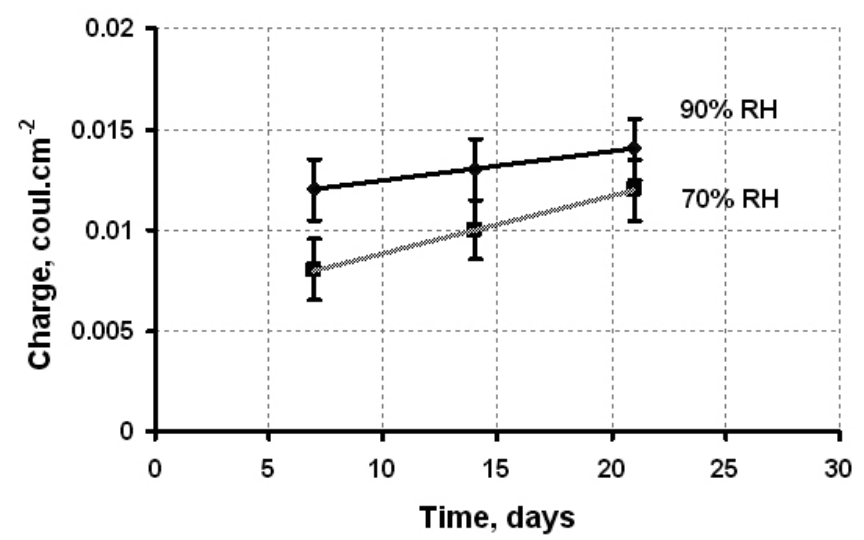

Figure 7.- Reduction charge in function of the exposure time for exposures with $260 \mathrm{ppbv}$ and relative humidities of 70 and $90 \%$.

Figure 8 displays variation of the corrosion rate, expressed in mdd (milligram per square decimeter day), for exposures with 4, 40, and $120 \mathrm{ppmv}$ propionic acid and three relative humidity levels. For relative humidity between 40 and $80 \%$, the corrosion rate is essentially the same, presenting corrosion rates within the standard deviation for the triplicate curves. However, all curves exhibit an increment in corrosion rate when is increase the pollutant concentration when relative humidity passes $80 \%$. Compared with the lower concentration ( $4 \mathrm{ppmv})$, the corrosion rates is almost four times with $40 \mathrm{ppmv}$, and almost ten times with 120 ppmv propionic acid. The same tendency has been found before ${ }^{27}$. From these results it seems that, $80 \%$ of relative humidity is critical for the atmospheric corrosion of copper in presence of propionic acid. The dispersion associated to these results may be related to an inherent error of the acid cleaning performed in the $10 \% \mathrm{H}_{2} \mathrm{SO}_{4}$ solution.

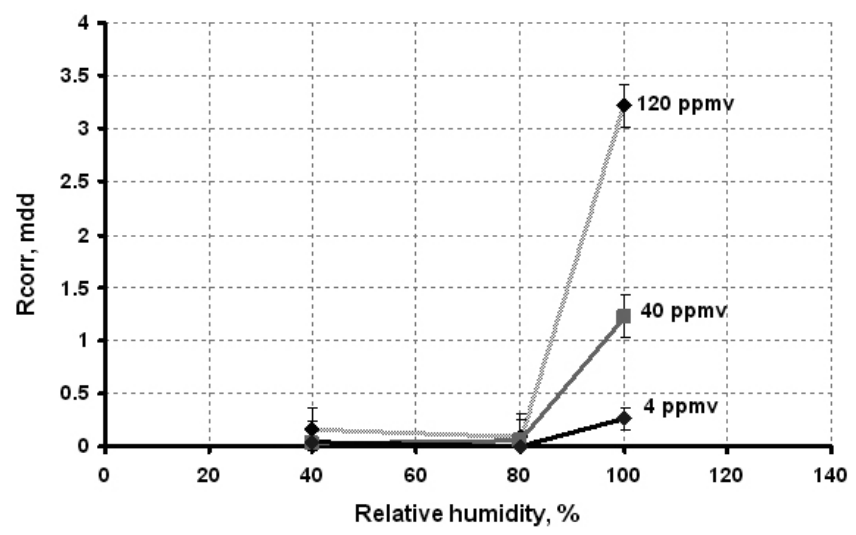

Figure 8.- Gravimetric corrosion rate against relative humidity pollutant concentration of 4,40 , and 120 ppmv propionic acid, under static conditions.

From the coulometric reduction data, the corrosion rate can be estimated using the following formula [4]:

$$
\operatorname{Vcorr}_{1}(m d d)=\frac{Q o x * M * 10^{5}}{F * d * n}
$$

where $Q_{o x}$, coul.cm-2, is the charge for the total oxides reduction, $\mathrm{M}$ is the copper molecular weight $\left(63.54\right.$ g.mol $\left.^{-1}\right), \mathrm{d}$ is the exposure time (days), $\mathrm{F}$ is the Faraday constant $\left(96500\right.$ coul.eq $\left.{ }^{-1}\right)$ and $\mathrm{n}$ is the valence number for the reduction (2).

It should be noticed that an $\mathrm{n}$-value of 2 is the one recommended for both, the ISO TC $156 /$ WG $4-\mathrm{N} 378$ standard $^{24}$ and the project TROPICORR, to estimate the corrosion rate from the coulometric reduction data ${ }^{25}$. On the other hand, this n-value has been previously questioned by Rocha et $a^{l^{6}}$, because of an underestimate corrosion rate. So, we propose, in order to get confidence on the corrosion rate, calculate it in function of the total cuprite reduction, including the three types of copper (I) oxides. In this way, the corrosion rate could be estimated as:

$\operatorname{Rcorr}_{2}(m d d)=\frac{Q \operatorname{Qox}\left(\mathrm{Cu}_{2} \mathrm{O}\right)_{e n} * M * 10^{5}}{F * d * 1}+\frac{Q \operatorname{oox}\left(\mathrm{Cu}_{2} \mathrm{O}\right)_{i n} * M * 10^{5}}{F * d * 2}+\frac{Q \operatorname{Oox}\left(\mathrm{Cu}_{2} \mathrm{O}\right)_{c r} * M * 10^{5}}{F * d * 2}$

Table III shows the comparison between the two corrosion rates estimated by both methods, during a exposure condition of $90 \%$ and $100 \% \mathrm{RH}$. The relation between the corrosion rates deduced using both techniques, approaches to the 1:1 ratio in the lowest corrosion rate values and by general rule, values below $0.05 \mathrm{mdd}$. The discrepancy in the high values of corrosion rate is evident, where the electrochemical technique predicts much lower estimation that the gravimetric ones. This could be due to an overestimation of the corrosion rate due to strong dissolution on the sulphuric acid. 
Table III.- Corrosion rate estimated according to the ISO TC 156/WG 4 - N 378 standard ${ }^{24}$ and the one proposed by Rocha et al. ${ }^{26}$ for exposures during 21 days at $90 \%$ and $100 \% \mathrm{RH}$ for the different concentrations of propionic acid.

\begin{tabular}{|c|c|c|c|c|}
\hline Concentration & $\begin{array}{c}\text { RH } \\
\mathbf{\%}\end{array}$ & $\begin{array}{c}\text { Rcorr, mdd, } \\
\text { (gravimetric) }\end{array}$ & $\begin{array}{c}\text { Rcorr1, mdd } \\
\text { (ISO) }\end{array}$ & $\begin{array}{c}\text { Rcorr 2, mdd } \\
\text { (Rocha } \text { et al) }\end{array}$ \\
\hline $260 \mathrm{ppbv}$ & 70 & $0.010 \pm 0.010$ & $0.0199 \pm 0.047$ & $0.0345 \pm 0.078$ \\
\hline $260 \mathrm{ppbv}$ & 90 & $0.010 \pm 0.010$ & $0.0219 \pm 0.047$ & $0.0398 \pm 0.078$ \\
\hline $380 \mathrm{ppbv}$ & 90 & $0.060 \pm 0.014$ & $0.0262 \pm 0.031$ & $0.0470 \pm 0.063$ \\
\hline $680 \mathrm{ppbv}$ & 90 & $0.055 \pm 0.014$ & $0.0293 \pm 0.047$ & $0.0502 \pm 0.078$ \\
\hline $680 \mathrm{ppbv}$ & 90 & $0.019 \pm 0.014$ & $0.0293 \pm 0.031$ & $0.0502 \pm 0.063$ \\
\hline $4 \mathrm{ppmv}$ & 100 & $0.258 \pm 0.151$ & $0.0317 \pm 0.0157$ & $0.0555 \pm 0.0219$ \\
\hline $40 \mathrm{ppmv}$ & 100 & $1.220 \pm 0.151$ & $0.5017 \pm 0.0470$ & $0.5252 \pm 0.0658$ \\
\hline
\end{tabular}

The ability to distinguish between the aggressiveness of the few polluted atmospheres, usually smaller than 700 ppbv, shows that the electrochemical technique is a reliable method to study this type of atmospheres. However, the gravimetric technique is more reliable than the electrochemical one, under high aggressiveness conditions, explained by a greater solubilization of the corrosion products leading to underestimate values of corrosion rates from the electrochemical data.

Likewise, it can be observed that the degradation rate (slope of the curve $\left.\mathrm{Q}_{\text {ox- } \mathrm{d}}\right)$ is approximately the same in ppbv concentrations $\left(0.003\right.$ coul. $\mathrm{cm}^{-2}$ day-1 $^{-1}$ ). But in the ppmv level, the corrosion rate increases with the propionic acid concentration in the air. For exposures with 4 ppmv the slope is 0.004 coul. $\mathrm{cm}^{-2}$.day ${ }^{-1}$ and for exposures in $20 \mathrm{ppmv}$ the slope is 0.0108 coul. $\mathrm{cm}^{-2}$. day $^{-1}$ (Table III)

Figure 9 compares the corrosion rate gravimetrically determined for the dynamic and static conditions. The data are reported in Table III.

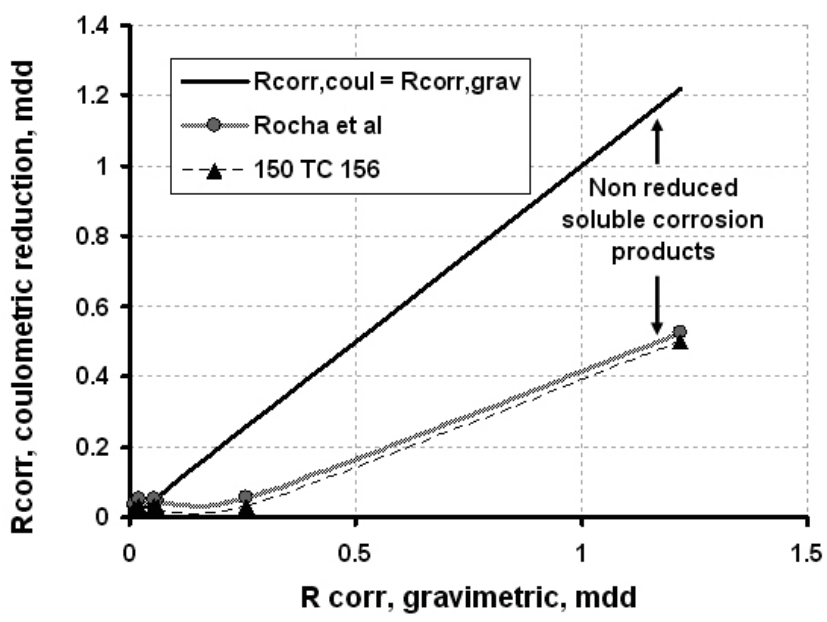

Figure 9.- Comparison between the corrosion rate determined from the coulometric reduction and the gravimetrically estimation.

General remarks-Atmospheric corrosion of copper in simulated environments containing propionic acid vapors, seems to be affected by small changes in the pollutant concentration and high relative humidities. These changes were possible to detect by using galvanostatic reduction performed over the corrosion products present on the samples. The reduction technique has been successfully applied before to the characterization and quantification of insoluble copper compounds in several types of environments. In our case, we choose the reduction charge used for the total reduction of the copper (I) oxide as a parameter to estimate the corrosion rate. It was found that the electrochemical technique is very sensible to this environment, and makes it useful to quantify the propionic acid attack. Just one copper oxide was electrochemically identified during the reduction. The copper oxide, exhibits three type of forms, namely amorphous, intermediate, and crustalline cuprite. These oxides were present in all of the experiments. It is reasonable to think that the oxides coexist with organic copper compounds such as any of the copper propionates. The lack of evidence of these organic carboxylates, can be interpreted as an associated high solubility of the organic compounds at least for the pollutant level tested.

Likewise, weight loss technique was used to measure the copper corrosion rate. When comparing the values from dynamic conditions (low pollutant level of ppbv) the data are confident using gravimetric, ISO and Rocha's method (Table III). But, when comparing with the results with static conditions (high pollutant level of ppmv), the values exhibit severe discrepancies making them unreliable to interpret the corrosion process.

Finally, gravimetric data were compared with the electrochemical results, showing some differences. When the traditional weight loss technique is applied to low propionic acid levels, turns out that the values present an overestimation probably associated to a large metal dissolution. In this case, we proposed to use the total reduction charge as estimation of the real corrosion rate.

The formation of a copper propionate can be proved by mean of complementary electrochemical and non-electrochemical techniques. The authors are currently working in a mechanism that explains the results of copper in presence of propionic acid vapors. In summary, the mechanism could be explained as follows: The first oxide layer cuprite $\left(\mathrm{Cu}_{2} \mathrm{O}\right)$ is instantly formed on the copper surface. This oxide, in presence of adsorbed water is oxidized further to copper oxide (II) $(\mathrm{CuO})$ simultaneously with a $\mathrm{pH}$ increase. The hydration of the tenorite layer induces the formation of a hydroxide such as $\mathrm{CuO} \cdot \mathrm{xH}_{2} \mathrm{O}$. As the pollutant level is increased in the atmosphere, insoluble basic propionate of the type $\mathrm{Cu}(\mathrm{OH})_{x}(\mathrm{Pro})_{2-\mathrm{x}}$ is formed. Higher concentrations of propionic acid in the atmosphere acidify much more the monolayers and a new compound $\mathrm{Cu}$ (Pro) ${ }_{2} \cdot \mathrm{H}_{2} \mathrm{O}$ begins to precipitate at low $\mathrm{pH}$. The mechanism is based on electrochemical reduction, XPS, XRD and SEM measurements, performed over copper samples from a propionic acid concentration ranging from 10 to $300 \mathrm{ppm}$. These results have been already published, verifying organic compound and copper oxide and hydroxide as main corrosion products. A cubic crustalite form of the cuprite is evident for greater corrosion rate ${ }^{27}$.

\section{CONCLUSIONS}

The coulometric reduction technique exhibits, statistically differences (with $95 \%$ of confidence) for the reduction charge of the copper (I) oxide obtained during the day 7 and the day 21 , at any concentration level of propionic acid. On the other hand, the data indicates an increment of approximately the same order, for the reduction charge value from the results obtained in 260 
ppbv, 380 ppbv, and 690 ppbv, at any exposure time. With this technique, it was possible to differentiate the corrosivity of the different environmental conditions evaluated.

The estimation of the corrosion rate by the electrochemical methods is not reliable when some corrosion products can be solubilized during the coulometric reduction experiments. The high dispersion of the gravimetric corrosion rate under low aggressiveness conditions was probably due to the inherent error related with the acid pickling procedure. However, a higher corrosion rate is observed between the 380 and 690 ppbv compared with 260 ppbv. Copper corrosion is increased slightly with the exposure time, but this deterioration is more evident for high relative humidities and concentrations of propionic acid.

\section{ACKNOWLEDGMENTS}

The authors want to express their gratefulness to CSIC/COLCIENCIAS in the project COLCIENCIAS 1115 - 11500 and to TROPICORR - Tropicalización de Materiales Electro-Electrónicos for the financial support of the study.

\section{REFERENCES}

1. A. Echavarría, C. Arroyave, E. Cano, F. Echeverría, J. M. Bastidas, Corr. Rev., 21, 395, (2003).

2. Graedel, T. E., Corros. Sci. 27, 721 (1987).

3. E. Cano, J. M. Bastidas, Metall. Quart., 41, 327, (2002).

4. A. López-Delgado, E. Cano, J. M. Bastidas, F. A. López, J. Electrochem. Soc. $145,4140,(1998)$.

5. J. M. Bastidas, A. López-Delgado, E. Cano, J. L. Polo, F. A. López, J. Electrochem. Soc. 147, 999, (2000).

6. E. Cano, M. F. López, J. Simancas, J. M. Bastidas, J. Electrochem. Soc. 148, E26, (2001).

7. E. Cano, E. M. Mora, M. Moorish, H. Ascaray, J. M. Bastidas, J. Electrochem. Soc., 151, B207-B213, (2004).
8. E. Cano, J. M. Bastidas, J. L. Polo, N. Mora, J. Electrochem. Soc. 148, B431, (2001).

9. E. Cano, E. M. Mora, H. Azcaray, J. A. López-Caballero, J. M. Bastidas, Proceedings of the Latincorr 2003, Santiago de Chile, Chile, 2003.

10. E. Cano, Proceedings of the IX Conference on Materials Science \& Technology, Madrid, España, 2003.

11. H. Gil, C. Leygraf, J. Electrochem. Soc., 154, C272, (2007).

12. H. Gil, C. Leygraf, J. Electrochem. Soc., 154, C611, (2007).

13. C. Leygraf, J. Hedberg, P. Qiu, H. Gil, J. Henriquez, C.M. Johnson, Corrosion, 63, 715, (2007).

14. Anuual Book of ASTM Standads, ASTM B-825-97.

15. S. J. Krumbein, J. Test. Eval., 357, (1989).

16. A. Echavarría, H. Vilca-Meléndez, I. Aoki, Proceedings of the Latincorr 2003, Santiago de Chile, Chile, 2003.

17. Anuual Book of ASTM Standads, ASTM G1-90.

18. H. Vilca-Meléndez, Doctoral Thesis, Escola Politécnica de Universidade de São Paulo. (2000).

19. H. Vilca-Meléndez, H, I. Aoki, Proceedings of NACE Brazil, São Paulo, 1999.

20. I. Aoki, H. Vilca-Meléndez, F. M. Arruda, A. G. Ceci, Mater. Sci. Forum, 292, 449, (1998).

21. I. Vieira Aoki and F. Gerjoil, Proceedings of the Corrosion in electroelectronic equipment. Brasil, 2000.

22. A. Echavarría, Doctoral Thesis, Universidad de Antioquia, (2004).

23. T. T. M. Tran, C. Fiaud, E. M. M. Sutter, A. Villanova, Corros. Sci., 45, $2787(2003)$

24. ISO/TC $156 / \mathrm{WG} 4-\mathrm{N} 358$.

25. F. Corvo, J. A. Rocha, CYTED. Productos electro-electrónicos en Ambientes tropicales, J. Rocha ed, Campinas, 2003.

26. J. A. Rocha, J. Rocha, and I. Aoki, Proceedings of Latincorr 2003, Santiago de Chile, Chile, 2003.

27. A. Echavarría, A. Rueda, E. Cano, F. Echeverría, C. Arroyave, J. M. Bastidas, J. Electrochem. Soc., 150, B140 (2003). 